Int. J. Electrochem. Sci., 14 (2019) 10043 - 10057

\title{
Simultaneous Electrochemical Determination of Hydroquinone and Catechol Using a Carboxylated Graphene/Poly-L- asparagine Modified Electrode
}

\author{
Yanrong Lu, Riya Jin", Yina Qiao, Jingmin Liu, Xiaojian Wang, Kun Wang, Chaoqi Wang \\ School of Environment and Safety Engineering, North University of China, Taiyuan 030051, China \\ *E-mail: jrya@nuc.edu.cn
}

doi: $10.20964 / 2019.11 .20$

Received: 2 June 2019 / Accepted: 9 August 2019 / Published: 7 October 2019

\begin{abstract}
In this study, a novel electrochemical sensor was developed by modifying carboxylated graphene/polyL-asparagine (CG/poly-L-Asn) on glassy carbon electrode (GCE) using a combination of electropolymerization and adsorption methods. The electrochemical catalytic activity of hydroquinone (HQ) and catechol (CC) was studied by cyclic voltammetry and differential pulse voltammetry. Under the optimized conditions, the peak potential difference between HQ and CC is $\sim 108 \mathrm{mV}$. This indicates the electrochemical sensor has anti-interference ability, and it can simultaneously detect these compounds. The limit of detection $(\mathrm{S} / \mathrm{N}=3)$ for $\mathrm{HQ}$ and $\mathrm{CC}$ is $0.0750 \mu \mathrm{M}$ and $0.1362 \mu \mathrm{M}$, respectively. The results show that the prepared CG/poly-L-Asn/GCE has good repeatability and sensitivity, and the proposed sensor can be prepared using a simple method with a low cost.
\end{abstract}

Keywords: Electropolymerization; Cyclic voltammetry; Differential pulse voltammetry; Hydroquinone; Catechol

\section{FULL TEXT}

(C) 2019 The Authors. Published by ESG (www.electrochemsci.org). This article is an open access article distributed under the terms and conditions of the Creative Commons Attribution license (http://creativecommons.org/licenses/by/4.0/). 